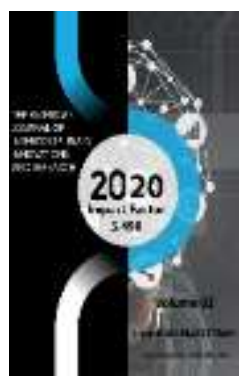

Journal Website: http://usajournalshub.c om/index,php/tajiir

Copyright: Original content from this work may be used under the terms of the creative commons attributes 4.0 licence.

\section{Linguoculturological Analysis Of Phraseological Units And Different Approaches To Linguoculturology}

\author{
Anora Javlievna Jabbarova \\ Senior Teacher Of Department English Practical Course, Jizzakh State Pedagogical Institute, \\ Uzbekistan
}

\title{
ABSTRACT
}

This article is about cultural linguistics, its main lexical and cultural factors, linguoculturological analysis of phraseological units. In it analyzed different approaches to cultural linguistics and relationship between culture and language.

\section{KEYWORDS}

Culture, linguistics, language, factors, approaches, culturology, linguo culturology, phraseological units.

\section{INTRODUCTION}

Cultural linguistics is a branch of linguistics that deals with the study of the relationship that arises between language and cultural concepts. Cultural linguistics is also called cultural linguistics. Cultural linguistics acts as a catalyst for the theoretical and analytical development of such scientific areas as: cognitive science is a multidisciplinary scientific direction that unites sciences that study the process of cognition and the functioning of human thinking from different positions; anthropology is a multidisciplinary scientific field that unites sciences that study a person as such, his origin and development, as 
well as existence in natural (natural) and cultural (artificial) environments. The direct subject of cultural linguistics is the diversity of reflections of existing and pre-existing languages with the help of their inherent special features of cultural concepts, which include cultural metaphors, cultural categories and cultural models.

Under a cultural concept, it is customary to understand the content of a linguistic unit (as a rule, words or phrases), behind which there is a concept (meaning) reflected in thinking, relating to the cultural sphere of a person's life. Culture is a concept that covers a huge range of issues and categories. The most widespread and widespread definition of "culture" is the sum of the many manifestations of human activity. In a narrow sense, culture is understood as a set of creative works characterized by the presence of spiritual value in society. Culture is the subject of a separate scientific discipline called culturology. And in the case of the relationship between culture and language (which is studied by linguistics) at the junction of theoretical teachings about them, a new science was formed - cultural linguistics or cultural linguistics.

\section{THE MAIN FINDINGS AND RESULTS}

Within the framework of the hypothesis of linguistic relativity, which is also called the Sapir-Whorf hypothesis, the existence of the influence of the structure of language on the worldview, mental and cognitive processes of its speakers is asserted. This assumption also applies to some extent to cultural linguistics, which in this concept is understood as a holistic study of objects. The essence of this research lies in the theoretical description of objects. The objects are cultural values
Cultural linguistics sees language as something rooted in the cultural (and therefore also at the group) level of cognition. Currently, the results of cultural linguistics, as well as the approaches used in it, are actively used in applied areas of linguistics, for example, in intercultural communication, in teaching and mastering a foreign language, as well as in contact variantology of the English language. However, according to some studies, the methods used for the purposes of linguoculturological research (first of all, establishing the direct dependence of culture on linguistic structures) do not meet the basic requirements of theoretical science. Based on this fact, cultural linguistics is often ranked among a number of pseudoscientific disciplines. Approaches to the definition of cultural linguistics In addition to the above generally accepted definition of cultural linguistics, some scholars, considering cultural linguistics from different points of view, offer their own interpretations of this concept. The main definitions of cultural linguistics, to which the overwhelming majority of definitions formulated by individual linguists can be attributed to one degree or another, are: the definition presented in the hypothesis of linguistic relativity; the definition given by V.V. Krasnykh; the definition given by $\mathrm{El}$ Zinovieva and EE Yurkov.

reflected in the language, which in their totality represent a functioning system. In addition, cultural linguistics can be called a contrastive analysis (that is, based on comparison) of the linguocultural spheres of different peoples and the languages they use. Moreover, this analysis should be based on the provisions of the hypothesis of linguistic relativity. Remark 2 Therefore, we can conclude that cultural linguistics (from the standpoint of the Sapir-Whorf hypothesis) is 
the study of culture that exists in linguistic form.

The Russian philologist V.V. Krasnykh considers cultural linguistics as a discipline that studies how culture manifests itself, is reflected and fixed in language and discourse. At the same time, the interrelation of this discipline with the study of the national picture of the world, linguistic consciousness, features of the mental-lingual complex is noted. Thus, from this point of view, cultural linguistics is in many ways similar to another linguistic discipline - ethnopsycholinguistics. That is, cultural linguistics studies the expression of culture in a language, depending on the national characteristics inherent in specific carriers and all the characteristics arising from them.

El Zinovieva and EE Yurkov defined cultural linguistics as a philological science, the main task of which is to study the diverse ways of representing knowledge about the world of speakers of a particular language. This research itself is the study of the language system and its units, speech activity and behavior of native speakers, as well as discourse. Consequently, cultural linguistics studies the culture of a particular society through the study of the language used in it.

1. Several directions have taken shape in cultural linguistics by now.

2. Culturology linguistics of a particular social group, ethnic group in some culturally bright period, ie, the study of a specific linguocultural situation.

3. Diachronic cultural linguistics, i.e. study of changes in the linguocultural state of an ethnic group over a certain period of time.

4. Comparative cultural linguistics, which investigates the linguistic and cultural manifestations of different, but interrelated ethnic groups.
5. Comparative cultural linguistics. It is just beginning to develop. Today it is represented by only a few works, the most interesting of which is the work of M. K. Golovanivskaya "The French mentality from the point of view of a native speaker of the Russian language", in which the peculiarities of the French mentality are studied from the standpoint of a native speaker of the Russian language and culture. The material for the analysis was abstract nouns in Russian and French - fate, danger, luck, soul, mind, conscience, thought, idea, etc.

6. Linguocultural lexicography, engaged in the compilation of linguistic and cultural dictionaries.

As you can see, the latter direction is developing especially actively. Let us briefly characterize one of the cited linguistic and cultural dictionaries, for example, DG Maltseva's dictionary. It contains 25 large thematic sections, arranged in no particular order. These are linguistic units that reflect the geographical realities of Germany, its climatic features, flora and fauna, the history of the country, old folk customs, beliefs, traditions, signs; old legends, symbolism of numbers, symbolism of color; weddings, funerals, holidays; religious beliefs, the development of the monetary system, measures of length, weight, volume, area, the history of industrial development, trade, science, technology, medicine; occurrence of a mail message; history of architecture and urban planning. Among the topics that are reflected in the dictionary, you can list the following: language, typography, writing, students and student life, school, nationallyspecific clothing items, traditional cuisine, games, folk dances, traditional greetings and wishes, etiquette phrases, national gestures, personal names and surnames, linguistic units 
of literary origin, aphorisms, German songs, national character. On the basis of such dictionaries, the study of the nature of the interaction of language and culture becomes quite productive.

With all the differences in existing directions, the subject of modern cultural linguistics is the study of the cultural semantics of linguistic signs, which is formed by the interaction of two different codes - language and culture, since each linguistic personality is also a cultural personality. Therefore, linguistic signs are capable of performing the function of the "language" of culture, which is expressed in the ability of the language to reflect the cultural and national mentality of its carriers. In this regard, we can talk about a "cultural barrier" that can arise even if all linguistic norms are observed. As an example, we can cite the case described by A. Vezhbitskaya with an English conductor, when he was invited to lead a German orchestra. The work was not going well. The conductor decided that this was due to the fact that he speaks English and the musicians do not perceive him as "theirs". He began to study the German language, and the first thing that asked the teacher how to say this phrase in German: "Look, I think it would be better if we played like this." The teacher pondered, then said: "Of course, you can construct a phrase like this, but it is better to say:" You have to play like this. "Hence the conclusion: the cultural barrier is associated with differences in the norms of speech behavior, as well as with different meanings that communication participants put into seemingly the same words, with inadequate background knowledge, etc.

Cultural linguistics as an independent branch of knowledge must solve its specific tasks and at the same time answer, first of all, a number of questions, which in the most general form can be formulated as follows:

1. How culture participates in the formation of linguistic concepts;

2. To which part of the meaning of a linguistic sign are "cultural meanings" attached;

3. Whether these meanings are realized by the speaker and the listener and how they influence speech strategies;

4. Is there in reality the cultural and linguistic competence of a native speaker, on the basis of which cultural meanings are embodied in texts and recognized by native speakers. As a working definition of cultural and linguistic competence, we take the following: this is the natural knowledge of the linguistic personality of the processes of speech production and speech perception and, which is especially important, the knowledge of cultural attitudes; to prove this, new technologies of linguocultural analysis of language units are needed;

5. What are the conceptual sphere (a set of basic concepts of a given culture), as well as cultural discourses, focused on the representation by carriers of one culture, a plurality of cultures (universals); cultural semantics of these linguistic signs, which is formed on the basis of the interaction of two different subject areas - language and culture;

6. How to systematize the basic concepts of this science, i.e. to create a conceptual apparatus that would not only allow analyzing the problem of interaction between language and culture in dynamics, but would provide mutual understanding within the framework of a given scientific paradigm - anthropological, or anthropocentric. 


\section{CONCLUSION}

The above list of tasks cannot be considered final, because progress in solving them will generate the next cycle of tasks, etc.These are the so-called high, or general epistemological, tasks that R.M. Frumkina considers common to all sciences, but there are still particular tasks related to the problem of translation, language teaching, compilation of dictionaries, where cultural information would be taken into account, etc. ... It seems that they can be solved only after solving "lofty" tasks, or at least with some advance in solving epistemological tasks.

\section{REFERENCES}

1. Benveniste E. General linguistics. M., 1974.

2. Vinogradov V.V. Stylistics. The theory of poetic speech. Poetics, M., 1963.

3. Vorobyov V.V. Linguoculturology. Theory and methods. M., 1997.

4. Gudkov D.B. Theory and practice of intercultural communication. M., 2003.

5. Maslova V.A. Linguoculturology. M. 2001.

6. Ismatullayeva N.R. Translation of phraseological units in Chinese and Uzbek languages. Scientific research of the SCO countries: synergy and integration (International conference). Beijing, PRC, June 24. Part 2, - pp. 45-50. DOI: 10.34660/INF.2020.44.20.001 